\title{
Produção de hidrogênio a partir do tratamento de efluente residual da produção de biodiesel
}

\section{Caio Fernando da Silva ${ }^{1}$, Flávia Maria Torres Lima ${ }^{1}$ e Luiz Antonio Pimentel Cavalcanti ${ }^{2}$}

${ }^{1}$ Instituto Federal de Educação, Ciência e Tecnologia da Bahia. Campus de Paulo Afonso. Curso de Graduação em Engenharia Elétrica. Rua Marcondes Ferraz, 200. Bairro General Dutra. Paulo Afonso-BA, Brasil (CEP 48607-000).

${ }^{2}$ Instituto Federal de Educação, Ciência e Tecnologia da Bahia. Campus de Paulo Afonso. Rua Marcondes Ferraz, 200. Bairro General Dutra. Paulo Afonso-BA (CEP 48607-000). E-mail: luiz.cavalcanti@ifba.edu.br.

Resumo. Nos últimos anos, as pesquisas sobre recursos renováveis vêm ganhando cada mais destaque devido à procura por um padrão de desenvolvimento mais sustentável em meio a uma sociedade com hábitos de consumo cada vez mais elevados. 0 biodiesel é uma opção de alternativa promissora, porém, o resíduo proveniente da etapa de lavagem da produção deste biocombustível é inadequado para descarte in natura ou reutilização. 0 presente trabalho buscou realizar o tratamento do efluente residual da produção do biodiesel através do processo de eletrofloculação/flotação e de forma simultânea avaliar a produção do gás hidrogênio presente na reação de tratamento. Foi desenvolvido um protótipo de um reator eletroquímico composto por dois eletrodos retangulares de ferro com $180 \mathrm{~mm} \mathrm{x}$ $20 \mathrm{~mm}$, com uma estrutura cilíndrica de PVC, fixando-se fios de arame cozido de aço que se ligam a uma fonte de tensão contínua (FA-3030) onde foi aplicada $15 \mathrm{~V}$. 0 protótipo desenvolvido tratou $400 \mathrm{~mL}$ de resíduo, onde as variáveis analisadas foram o pH, DBO, DQO, turbidez, óleos e graxas, o tratamento alcançou um fator de melhora nas variáveis analisadas de $85 \%$ comprovando a eficiência do processo realizado, em conjunto com o tratamento do efluente houve êxito na produção de hidrogênio que apresentou com uma vazão de 1,06 L/h.

Palavras-chave: Biodiesel; Produção de hidrogênio; Reator eletroquímico.

\begin{abstract}
Hydrogen production a part of residual effluent treatment of biodiesel production. In recent years research on renewable resources has been gaining more prominence due to the search for a more sustainable development pattern in a society with increasingly high consumption habits. A promising alternative is the production of hydrogen through the process of electrolysis of water. The present work searches through the process of electro flotation/flotation present in the treatment of residual effluents in the production of biodiesel to obtain the
\end{abstract}

Recebido:

$26 / 05 / 2019$

Aceito:

$20 / 07 / 2019$

Disponível on line:

$21 / 07 / 2019$

Publicado:

$31 / 08 / 2019$

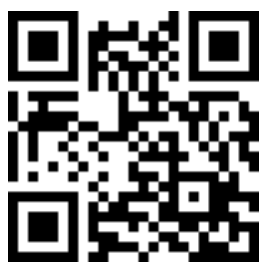

Acesso aberto

ORCID

(D) 0000-0001-8487-9064 Caio Fernando da Silva

(b) 0000-0001-8483-8384

Flávia Maria Torres

Lima

D) 0000-0003-4932-9387

Luiz Antonio Pimentel

Cavalcanti 
hydrogen gas. It was developed a prototype of an electrochemical reactor composed of two rectangular iron electrodes with 180 $\mathrm{mm} \times 20 \mathrm{~mm}$, where $15 \mathrm{~V}$ and a cylindrical structure of PVC was applied, fixing baked steel wire that attach to a continuous voltage source (FA-3030). Through the results obtained it is possible to verify that the realization of the prototype obtained a significant gain for the hydrogen production.

Keywords: Biodiesel; Hydrogen; Electrochemical reactor.

\section{Introdução}

A sociedade contemporânea é dependente de combustíveis fosseis principalmente petróleo e gás natural, os danos causados ao meio ambiente devido à utilização de seus respectivos derivados e petroquímicos em conjunto com a cobrança em relação às gerações futuras devido ao caráter não renovável desses combustíveis, fomenta a busca por alternativas mais benéficas ao meio ambiente. 0 biodiesel é uma alternativa ambientalmente vantajosa, pois sua obtenção é realizada a partir de matérias-primas mais benéficas a natureza como óleos vegetais, gordura animal e algas (Cordeiro et al., 2015).

0 biodiesel, apesar de todas as vantagens ambientais que apresenta, possui a particularidade de necessitar de um processo de lavagem que consiste na retirada de quantidades excedentes de álcoois, glicerina, catalisador e do óleo usado como reagente (Guimarães, 2013), o descarte do efluente resultante do processo de lavagem em corpos hídricos sem nenhum tratamento prévio, de acordo com Braga (2012) é danoso ao meio ambiente. Boni et al. (2007) alerta para os maiores custos de tratamento de esgoto em uma determinada região, que são gerados pelo descarte do efluente residual da produção de biodiesel, a partir dos fatos apresentados é possível concluir a importância do tratamento de efluentes poluidores.

0 processo eletroquímico vem ganhando destaque no tratamento de efluentes poluidores, como, por exemplo, os resíduos da indústria têxtil (Fleck et al., 2013) e os efluentes da indústria de processamento de coco por meio da eletrofloculação, onde a reação de eletrólise é capaz de desestabilizar as fases agregadas e ocasionar a formação de flocos e então torna-se possível a eliminação do poluente por um processo simples de filtração (Crespilho e Rezende, 2014).

0 reator eletroquímico usado para tratamento do efluente residual da produção do Biodiesel tem por principio um processo eletrolítico no qual ocorre a quebra de ligações entre as moléculas de hidrogênio e oxigênio. Para tal quebra, a célula faz uso de uma fonte de corrente elétrica contínua, onde esta possui dois eletrodos de ferro imersos em um determinado fluido e separados a uma distância adequada para aumentar a condutividade das moléculas (Leludak e Haus, 2013).

A partir do tratamento da água do processo de lavagem do biodiesel é possível produzir o gás hidrogênio de maneira eficiente. Sabe-se que o gás hidrogênio praticamente não é encontrado em estado livre na natureza, sendo este associado a outros elementos com os quais se combinam dificultando sua coleta e aplicações tecnológicas. Grande parte da produção de hidrogênio advém de fontes de hidrocarbonetos como o gás natural, carvão e petróleo, porém, através processo de eletrólise, presente no processo de tratamento do efluente residual da produção do biodiesel é possível obter hidrogênio e oxigênio causando impactos mínimos ao meio ambiente (Rottava, 2013).

A partir do exposto, o objetivo deste trabalho consiste em avaliar a eficiência da produção de hidrogênio 
oriunda do processo de tratamento do efluente residual da produção do biodiesel, onde o protótipo de reator eletroquímico é capaz de realizar a separação dos gases hidrogênio e oxigênio, posteriormente este trabalho também se propõe a analisar as variáveis físicas e químicas do efluente para avaliar a eficiência do tratamento.

\section{Materiais e métodos}

A aquisição dos materiais para construção e montagem do protótipo elencados na Tabela 1, ocorreu em estabelecimentos comerciais do ramo da construção civil, localizados no Município de Paulo Afonso no Estado da Bahia, os demais materiais e o apoio logístico foram disponibilizados pelo Instituto Federal de Educação, Ciência e Tecnologia da Bahia (IFBA), Campus Paulo Afonso.

\section{Dispositivo de eletrofloculação}

A produção do hidrogênio e oxigênio a partir do tratamento do efluente residual da produção de biodiesel utilizou o principio do gerador HHO, a estrutura do protótipo, porém, possibilita a coleta dos gases hidrogênio e oxigênio de forma separada, a partir da consulta literatura especializada foi possível concluir que o PVC e o ferro são materiais adequados e de baixo custo para compor, respectivamente, a estrutura e os eletrodos (Cordeiro et al., 2015).

Tabela 1. Materiais utilizados na construção do protótipo.

\begin{tabular}{|l|c|c|}
\hline Material & Quantidade & Situação \\
\hline $\begin{array}{l}\text { Tubo de PVC com } 20 \mathrm{~mm} \text { de diâmetro e } 200 \mathrm{~mm} \\
\text { de comprimento. }\end{array}$ & 2 unid. \\
\hline $\begin{array}{l}\text { Tubo de PVC com } 100 \mathrm{~mm} \text { de diâmetro e } 130 \\
\text { mm de comprimento. }\end{array}$ & 1 unid. & Novo \\
\hline $\begin{array}{l}\text { Tampa de PVC para vedação com } 40 \mathrm{~mm} \text { de } \\
\text { diâmetro e 20 mm de comprimento. }\end{array}$ & 2 unid. & Novo \\
\hline $\begin{array}{l}\text { Tampa de PVC para vedação com } 100 \mathrm{~mm} \text { de } \\
\text { diâmetro e 20 mm de comprimento. }\end{array}$ & 2 unid. & Novo \\
\hline $\begin{array}{l}\text { Parafuso de aço inoxidável com } 2 \mathrm{~mm} \mathrm{de} \\
\text { diâmetro e } 40 \text { mm de comprimento. }\end{array}$ & 2 unid. & Reutilizado \\
\hline Mangueira transparente. & $1,4 \mathrm{~m}$ & Reutilizado \\
\hline $\begin{array}{l}\text { Placas de ferro com } 180 \text { mm de comprimento, } \\
20 \text { mm de largura e 3 mm de espessura. }\end{array}$ & 4 unid. & Reutilizado \\
\hline Arame de aço; & $200 \mathrm{~mm}$ & \\
\hline
\end{tabular}

A montagem preliminar do protótipo consiste na afixação de uma unidade do tampão de vedação em um dos lados do tubo de $100 \mathrm{~mm}$ de diâmetro com cola específica para PVC, enquanto que a outra unidade do tampão de vedação é perfurada com dois furos de $40 \mathrm{~mm}$ de diâmetro e afixada na outra extremidade do tubo de $100 \mathrm{~mm}$ de diâmetro, as duas unidades de tampões de $40 \mathrm{~mm}$ de diâmetro foram perfuradas com o objetivo de realizar a inserção dos parafusos de aço inoxidável (parte integrante do conjunto de eletrodos) e dutos de captação de gás, logo em seguida as peças moveis são encaixadas como mostrado na Figura 1. 



Figura 1. Etapas de montagem do protótipo.

0 reator eletroquímico foi idealizado para tratar de forma eficiente uma quantidade mínima de efluente mínima de $250 \mathrm{~mL}$ e uma quantidade máxima de $1 \mathrm{~L}$ de efluente residual da produção de Biodiesel, a diferença de potencial elétrica necessária ao processo de eletrofloculação foi aplicada aos eletrodos utilizando uma fonte de tensão continua marca Instrutherm, modelo FA 3030.

O efluente residual obtido na lavagem do Biodiesel, produzido pela reação de transesterificação alcalina por rota metílica do óleo de soja com o catalisador formado a partir da mistura de $2 \mathrm{~g}$ de hidróxido de sódio e $60 \mathrm{~mL}$ de metanol, foram coletados um total de
$700 \mathrm{~mL}$ de resíduo do qual $400 \mathrm{~mL}$ foram destinados à realização do experimento $\mathrm{e}$ uma alíquota de $300 \mathrm{~mL}$ foi mantida em estado bruto para posterior avaliação da eficiência do processo de tratamento.

As características construtivas do reator eletroquímico como a distância entre os eletrodos, volume tratado e dimensões dos eletrodos são mantidas fixas, as condições de operação são definidas de acordo com a pesquisa de Cordeiro et al. (2015), que enuncia que o tempo de tratamento de $10 \mathrm{~min}$ possibilita uma eletrofloculação eficiente em conjunto com uma melhor utilização do recurso energético, a fim de ajustar a condutividade da solução foram adicionadas $1 \mathrm{~g}$ de cloreto de sódio 
$(\mathrm{NaCl})$ para cada $100 \mathrm{~mL}$ de efluente tratado, somando $4 \mathrm{~g}$ de $\mathrm{NaCl}$ adicionadas, a diferença de potencial
(DDP) aplicada foi de $15 \mathrm{~V}$, com uma corrente de aproximadamente 2,4 A.

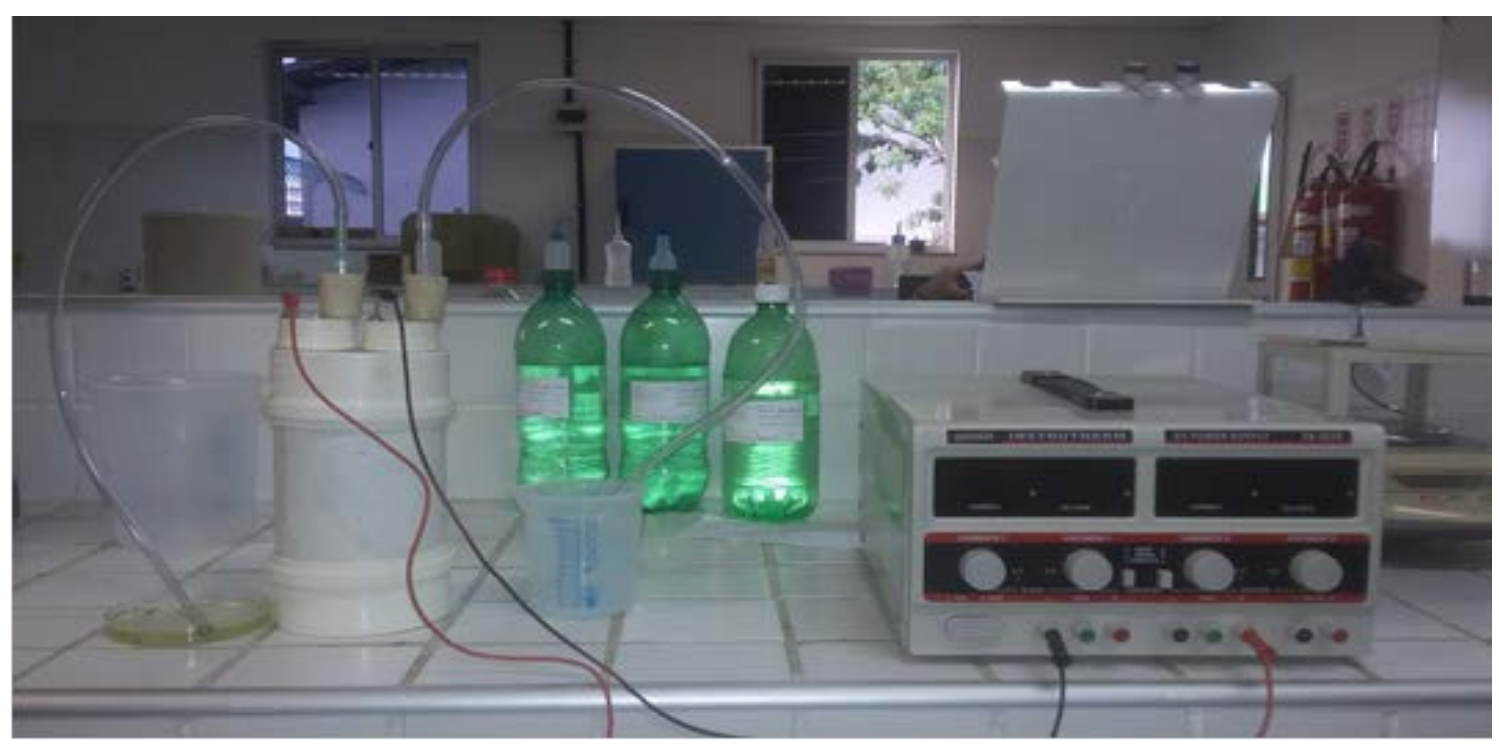

Figura 2. Protótipo do reator eletroquímico.

A comprovação do êxito do protótipo em produzir hidrogênio ocorreu através do método de borbulhamento do hidrogênio gerado em um recipiente contendo uma solução diluída de água e detergente com exposição dos gases gerados a uma pequena chama onde $\mathrm{o}$ alto poder calorifico do gás hidrogênio gerou um "estampido". A medida de vazão do hidrogênio produzido foi realizada através de um bolhômetro construído de maneira artesanal aproveitando uma proveta plástica de $250 \mathrm{~mL}$ no laboratório de Química, do Instituto Federal de Educação, Ciência e Tecnologia da Bahia (IFBA), Campus Paulo Afonso, na realização do experimento o bolhômetro foi acoplado em série ao duto de captação de gás hidrogênio (Figura 3).

Figura 3. Bolhômetro. 


\section{pH}

$\mathrm{O} \mathrm{pH}$ da amostra tratada foi medido em um pHmetro digital (Quimis, modelo Q400AS), adequadamente calibrado a $24^{\circ} \mathrm{C}$ (Eaton et al., 2005).

\section{Turbidez}

A avaliação da turbidez ocorreu através do método nefelométrico (Eaton et al., 2005), em turbidímetro de bancada (Turbidímetro Multiprocessado DLM 2000B, Del Lab®).

\section{DBO e DQO}

O DQO foi analisado pelo método colorimétrico (Standard Methods 5220 D), (Eaton et al., 2005), em conjunto um com bloco digestor do tipo TE-021 Dry Block Digestor (TECNAL), posteriormente a quantificação do DQO foi realizada através de espectrofotometria (Spectrophotometer SP1105, Bel Photonics), definindo como branco um padrão de água destilada (BioClass). As análises de DBO recorreram ao método definido no Standard Methods $5210 \mathrm{~B}$ (Eaton et al., 2005), com determinação quantitativa posterior das amostras em um oxímetro (Digimed, modelo DM-4D).

\section{óleos e graxas}

O teor de óleos e graxas foi determinado pelo método gravimétrico através da extração líquido-líquido (Eaton et al., 2005).

\section{Resultados e discussão}

0 efluente residual da produção de biodiesel pós-tratamento, pôde ser filtrado e o aspecto visual resultante é mostrado na Figura 4, o aspecto visual límpido da amostra é um indicativo de êxito no tratamento do efluente (Meneses et al., 2013), a partir da previa análise visual comprovou-se a viabilidade do envio da amostra tratada para análise laboratorial, a decomposição dos eletrodos de ferro durante a eletrólise ocasiona um aumento da condutividade do efluente ao longo do tempo, tal fato explica a variação de corrente verificada durante a reação, porém, mesmo com a deposição de partículas de ferro durante o processo de tratamento a utilização do $\mathrm{NaCl}$ para ajuste da condutividade do efluente fezse necessária.

O tempo de $10 \mathrm{~min}$ de tratamento, assim como mostrado pelo estudo de Cordeiro et al. (2015), proporcionou um maior controle sobre o processo de reação dos eletrodos de ferro e um menor consumo energético. A Figura 4 apresenta o efluente bruto à esquerda e efluente tratado após o processo de eletrofloculação (à direita).

As análises realizadas em laboratório, norteadas pela Resolução CONAMA no 430/2011 (Brasil, 2011), avaliaram pH, turbidez, DQO, DBO, óleos e graxas.

O comparativo entre os resultados obtidos com a análise laboratorial do efluente bruto e tratado está disposto na Tabela 1.

Os dados contidos na Tabela 1sinalizam que a melhora da qualidade do efluente implica na diminuição dos valores de turbidez, DQO, DBO, óleos e graxas, apenas o valor de $\mathrm{pH}$ que não possui uma relação diretamente linear com a qualidade do efluente devendo estar com um valor entre 5 e 9. 


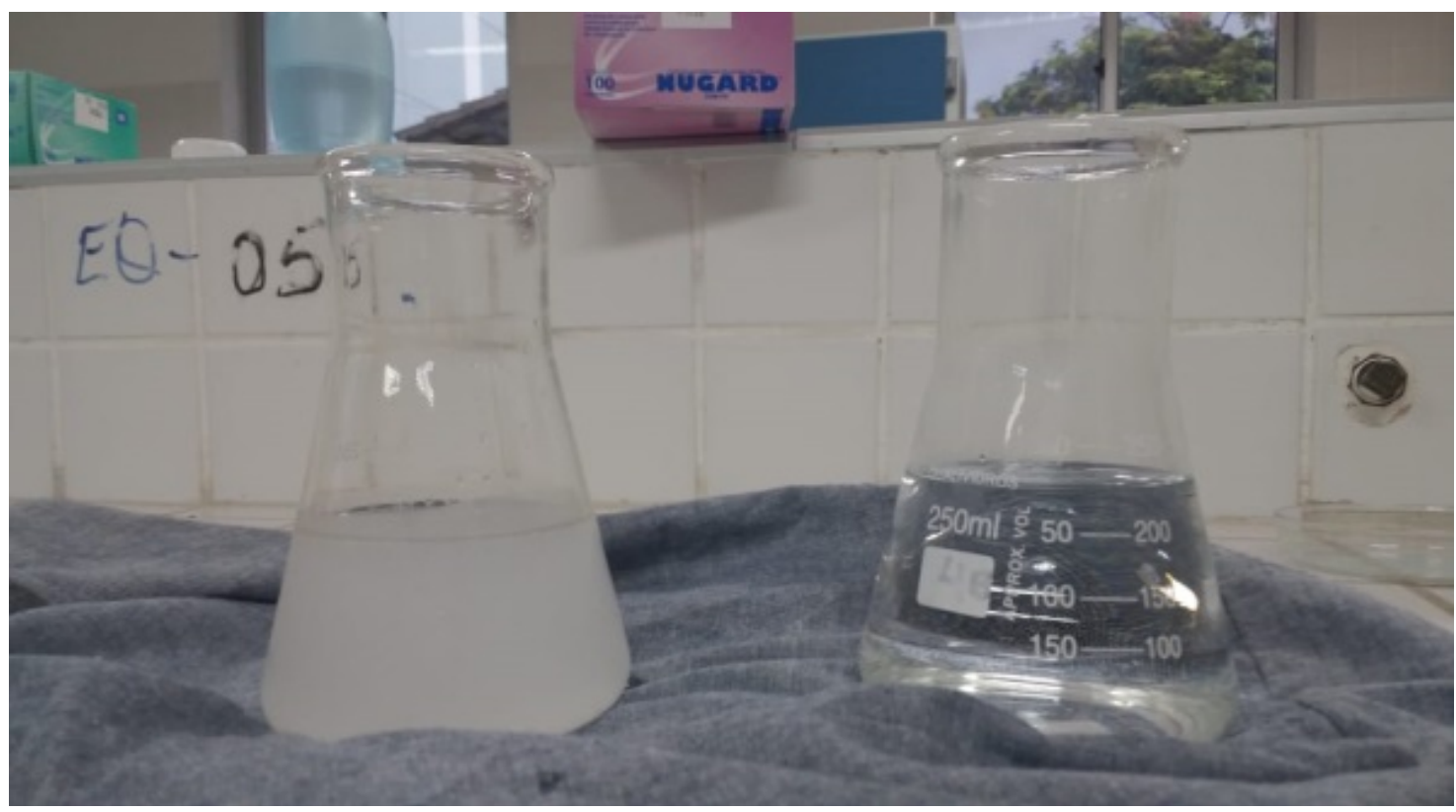

Figura 4. Resíduo antes e depois do tratamento.

Tabela 1. Resultado analise em laboratório.

\begin{tabular}{|l|r|r|r|r|r|}
\hline & \multicolumn{1}{|c|}{$\mathrm{pH}$} & Turbidez (NTU) & DQO (mg/L) & DBO (mg/L) & Oleos e Graxas (mg/L) \\
\hline Efluente Bruto & 3,26 & 490 & 5400 & 2350 & 595 \\
\hline Efluente Tratado & 5,98 & 73,5 & 972 & 963,5 & 345,1 \\
\hline
\end{tabular}

Avaliando percentualmente a diminuição dos valores das variáveis físicas e químicas é possível verificar para turbidez uma diminuição de $85 \%$ do valor original, realizando a mesma análise para DBO e DQO encontra-se uma diminuição, respectivamente, de $82 \%$ e $59 \%$, por fim óleos e graxas mostraram uma diminuição de $85 \%$.

A teoria a respeito do processo eletrolítico prevê que no cátodo ocorre a geração de hidrogênio e no ânodo ocorre a geração de oxigênio (Liberato Neto e Moreira, 2007) o reator eletroquímico construído realiza a separação dos gases hidrogênio e oxigênio produzidos, assim como esperado no teste da chama as bolhas geradas pelo cátodo ocasionaram um estampido enquanto que as bolhas no ânodo não causaram nenhuma reação comprovando a produção de hidrogênio no reator eletroquímico, a utilização do bolhômetro na conjuntura do experimento teve o objetivo de verificar a vazão de hidrogênio durante o processo de tratamento do efluente no reator eletroquímico, com a utilização deste aparelho medidor foi possível aferir uma vazão de $1,06 \mathrm{~L} / \mathrm{h}$.

\section{Conclusão}

Os valores apresentados nos resultados da análise em laboratório apresentam diminuições significativas dos valores de DBO, DQO, óleos e graxas e a mudança do $\mathrm{pH}$ de um meio ácido representado pelo $\mathrm{pH} \mathrm{3,26}$ para o valor adequado de 5,98, a partir de tais resultados é possível comprovar a eficiência do tratamento.

$\mathrm{Na}$ avaliação de custo e benefício do protótipo o êxito do tratamento comprova o tempo de tratamento de 
10 min como ideal para oferecer um tratamento satisfatório em conjunto com um baixo consumo do recurso energético.

Um fator observado durante os experimentos foi a influência da quantidade de concentração de $\mathrm{NaCl}$ adicionada ao reator para maior condutividade elétrica, uma boa condutividade se mostrou como um característica importante tanto para a produção de hidrogênio quanto para o processo de tratamento, juntamente com a carga fornecida na fonte de tensão, a metodologia utilizada de adicionar $1 \mathrm{~g}$ de $\mathrm{NaCl}$ para cada $100 \mathrm{~mL}$ de efluente produzido se mostrou como uma condição de operação eficiente para se obter uma valor de condutividade adequado.

A vazão de hidrogênio aferida indica uma produção de hidrogênio de $1,06 \mathrm{~L} / \mathrm{h}$ de gás produzido, indica-se como método para aumentar a produção de hidrogênio o emprego de vários reatores operando em paralelo, tal opção se mostra como viável devido ao baixo custo de produção do protótipo projetase que 10 reatores em paralelo são capazes alcançar em media uma vazão de 10,6 L/h.

A operação do reator eletroquímico em conjunto com fontes de energia renovável como a solar e a eólica se mostram como uma alternativa viável para aumentar a eficiência, já que a adoção de tal alternativa eliminaria o custo com a utilização do recurso energético.

\section{Conflito de interesses}

Os autores declaram não haver conflito de interesses.

\section{Referências}

Braga, E. D. A. S. Caracterização das águas de lavagem provenientes da etapa de purificação da produção de biodiesel de óleo de tilápia. Fortaleza: Universidade Federal do Ceará, 2012. (Tese de doutorado).
Boni, L. A. B.; Goldani, E.; Milcharek, C. D.; Santos, F. A. Tratamento físico-químico da água de lavagem proveniente da purificação do biodiesel. Periódico Tchê Química, v. 4, n. 7, p. 41-50, 2007. Disponível em: <http://www.deboni.he.com.br/revista7.pdf $>$. Acesso em: 14 maio 2019.

Cordeiro, B. R.; Alexandre, J. I. S.; Silva, J. P. F.; Sales, D. C. S.; Cavalcanti, L. A. P. Purificação e reutilização de águas residuais da produção de biodiesel por meio da eletrofloculação. Revista Brasileira de Gestão Ambiental e Sustentabilidade, v. 2, n. 2, p. 51-58, 2015. Disponível em: <http://revista.ecogestao brasil.net/v2n2/v02n02a05a.html>. Acesso em: 14 maio 2019.

Crespilho, F. N.; Rezende, M. O. O. Eletroflotação: princípios e aplicações. 1. ed. São Carlos: Rima, 2004

Eaton, A. D.; Clesceri, L. S.; Rice, E. W.; Greenberg, A. E.; Franson, M. A. H. (Ed.). Standard methods for the examination of water and wastewater. 21. ed. Washington: American Public Health Association, 2005.

Fleck, L.; Tavares, M. H. F.; Eyng, E. Utilização da técnica de eletrofloculação para o tratamento de efluentes têxteis: uma revisão. Revista Eixo, v. 2, n. 2, p. 51-65, 2013. https://doi.org/10.19123/eixo.v2i2. 107

Guimarães, P.S. Tratamento de águas residuárias oriundas da purificação do biodiesel por coagulação empregando sulfato de alumínio e quitosana: avaliação preliminar. Brasília: Universidade de Brasília, 2013. (Dissertação de mestrado).

Leludak, T.F.; Haus, T. L. Célula de hidrogênio: estudo e construção de uma célula eletrolítica para produção de hidrogênio gasoso. Caderno PAIC, v. 14, n. 1, p. 383-397, 2013.

Liberato Neto, R.; Moreira, J. R. S. Geração e combustão do hidrogênio obtido através do processo de eletrólise da água. São Paulo: Universidade de São Paulo, 2007. Disponível em: <http://sites.poli.usp.br/d/ pme2600/2007/Artigos/Art_TCC_018_2007. pdf>. Acesso em: 14 maio 2019.

Meneses, M. J. Tratamento do efluente do biodiesel utilizando a eletrocoagulação/ flotação: investigação dos parâmetros operacionais. Química Nova, v. 35, n. 2, p. 235-240, 2012. https://doi.org/ 10.1590/S0100-40422012000200002 
Rottava, W. Estimativa de produção de hidrogênio para aplicação em célula a combustível: estudo de caso - Granja Colombari. Curitiba: Universidade Federal do Paraná, 2013. (Monografia de graduação).

CC Informação da Licença: Este é um artigo Open Access distribuído sob os termos da Licença Creative Commons Attribution, que permite uso irrestrito, distribuição e reprodução em qualquer meio, desde que a obra original seja devidamente citada. 